\title{
MALTRATO FISICO-PSICOLOGICO Y AUTOESTIMA-ASERTIVIDAD EN NIÑOS Y NIÑAS DE LAS INSTITUCIONES EDUCATIVAS DEL AREA RURAL DE LA LOCALIDAD DE HUANCAVELICA 2010
}

\section{PHYSICAL AND PSYCHOLOGICAL ABUSE AND SELF-ASSERTIVENESS IN CHILDREN OF EDUCATIONAL INSTITUTIONS OF RURAL AREA IN THE TOWN OF HUANCAVELICA 2010}

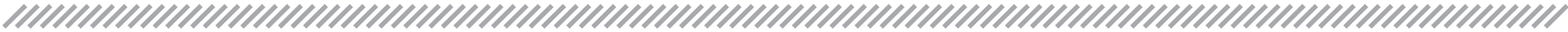 \\ AUTORES: Huamán Albites Margarita Isabel1, Gonzales Paco Edwin², Flores Marín Guido², Huamán Ulloa \\ Paul José, Torres Escobar Rosario ${ }^{5}$
}

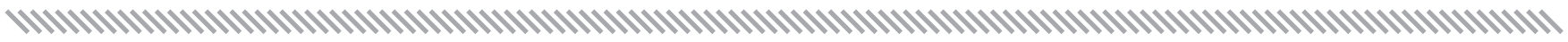

\section{RESUMEN}

OBJETIVO: Determinar la relación que existe entre el maltrato físico, psicológico con la autoestima y asertividad en los niños y niñas de las Instituciones Educativas del área rural de la Localidad del Distrito de Huancavelica-2010.

MÉTODOS: Tipo observacional, nivel descriptivo, diseño correlacional, métodos descriptivo, inductivo-deductivo, población 22 alumnos, muestro no probabilístico criterial.

RESULTADOS: $45.5 \%$ fueron niños y $54.5 \%$ niñas. $40.9 \%$ sufrieron maltrato físico severo, de ellos $4.5 \%$ tuvieron autoestima alta, $18.2 \%$ tendencia autoestima alta, $13.6 \%$ tendencia a autoestima baja y $4.5 \%$ autoestima baja. El 13.6\% de maltratados físicamente, 3.6\% fue moderado; de los cuales $4.5 \%$ tuvieron tendencia a una autoestima alta, autoestima en riesgo, tendencia a autoestima baja; del $45.5 \%$ de niños no maltratados un $31.8 \%$ mostraron una tendencia a autoestima alta, $47.5 \%$ autoestima en riesgo y $9.1 \%$ tendencia a autoestima baja. Las víctimas de maltrato físico severo, mostraron una asertividad de $40.9 \%$ medio y los de maltrato físico moderado mostraron una asertividad $4.5 \%$ alta y $9.1 \%$ medio; los niños que no fueron víctimas de maltrata físico mostraron una asertividad $31.8 \%$ alta y $13.6 \%$ medio. El 13.6\% sufrieron maltrato psicológico tanto leve como moderado y $27.3 \%$ severo. Las víctimas de maltrato psicológico severo mostraron $18.2 \%$ tendencia a alta autoestima, $4.5 \%$ autoestima en riesgo $\mathrm{y}$ tendencia a baja autoestima. Las víctimas de maltrato psicológico moderado mostraron $4.5 \%$ tendencia au- toestima alta y $9.1 \%$ tendencia autoestima baja y las víctimas de maltrato psicológico leve mostraron 9.1\% tendencia autoestima alta y $4.5 \%$ tendencia autoestima baja; los resultados muestran que las víctimas de maltrato psicológico severo mostraron una asertividad de $4.5 \%$ en alto y $22.7 \%$ medio, las víctimas de maltrato psicológico moderado mostraron una asertividad de $13.6 \%$ medio y las víctimas de maltrato psicológico leve mostraron una asertividad de $9.1 \%$ alto y $4.5 \%$ medio.

CONCLUSIONES: Los niños(as) fueron víctimas de maltrato físico severo en un porcentaje mayor, encontrándose un bajo porcentaje de niños(as) con tendencia a autoestima baja y a una autoestima baja, así mismo mostraron un mayor porcentaje de asertividad en el nivel medio. Las víctimas de maltrato psicológico en sus diferentes categorías, mostraron una fluctuación de la autoestima entre la tendencia a la autoestima alta, así como a una autoestima baja, con respecto a la asertividad mostraron un nivel medio. Según la prueba estadística Ji Cuadrada, existe asociación muy significativa entre el maltrato físico y psicológico con el nivel de asertividad, con un $\mathrm{p}=0,007, \mathrm{y} p=0.021$ Así mismo se encontró evidencia para afirmar que existe asociación significativa entre el maltrato físico y psicológico con la autoestima $\mathrm{p}=0,041, \mathrm{y}=0.043$. En cuento al maltrato físico y la autoestima con un $\mathrm{p}=0,551$; se señala que no existe relación significativa entre las variables de estudio. Finalmente en cuanto al maltrato psicológico y autoestima con un $\mathrm{p}=0,914$; se evidencia que no existe relación entre las variables de estudio.

PALABRAS CLAVES: Maltrato físico y psicológico, 
autoestima, asertividad, alumno.

\begin{abstract}
OBJECTIVE: To determine the relationship between the physical, psychological self-esteem and assertiveness in children Educational Institutions in rural areas of the Parish of Huancavelica District 2010.

METHODS: A quantitative, descriptive level, correlational design, descriptive methods, inductive -deductive, population 22 students, non-probability sampling criterial.
\end{abstract}

RESULTS: $45.5 \%$ were boys and $54.5 \%$ girls. 40.9 $\%$ suffered severe physical abuse, of which $4.5 \%$ had high self esteem, high self-esteem trend $18.2 \%, 13.6$ $\%$ tendency to low self esteem and low self-esteem $4.5 \%$. The $13.6 \%$ of physically abused , $3.6 \%$ were moderate, of which $4.5 \%$ had a tendency toward high self-esteem, self-esteem at risk, prone to low self-esteem , $45.5 \%$ of children abused $31.8 \%$ showed a tendency to high self-esteem, self-esteem at risk $47.5 \%$ and $9.1 \%$ tendency to low self esteem. The victims of severe physical abuse, showed a $40.9 \%$ average assertiveness and moderate physical abuse showed a high assertiveness $4.5 \%$ and $9.1 \%$ average , children who were not physically abused victims showed high assertiveness $31.8 \%$ and $13.6 \%$ average. The $13.6 \%$ suffered psychological abuse both mild and moderate and $27.3 \%$ severe. The victims of severe emotional abuse $18.2 \%$ showed high self-esteem trend, $4.5 \%$ self at risk and prone to low self-esteem. Victims of psychological abuse showed moderate $4.5 \%$ trend high esteem and low self-esteem $9.1 \%$ trend and victims of psychological abuse showed slight trend $9.1 \%$ and $4.5 \%$ high esteem low self esteem trend, the results show that victims of severe psychological abuse showed a assertiveness of $4.5 \%$ at high and $22.7 \%$ average, moderate psychological abuse victims showed a $13.6 \%$ average assertiveness and psychological abuse victims showed mild assertiveness $9.1 \%$ higher and $4.5 \%$ medium.

CONCLUSIONS: Children (as) were victims of severe physical abuse at a higher rate, being a low percentage of children (as) with a tendency to low self esteem and low self-esteem, also showed a higher percentage of assertiveness on the middle level. Victims of psychological abuse in different categories, showed a fluctuating trend esteem between high self-esteem and a low self esteem, assertiveness regarding showed a medium level. Nonparametric statistical test Chi-square, $\mathrm{p}=0.05$, concluding that there is significant association between physical abuse and level of assertiveness, with $\mathrm{p}=$ 0.007. It also found evidence to say that there is significant association between psychological abuse and level of assertiveness $p=0.194$. In tale of physical abuse and self-esteem with a $\mathrm{p}=0.551$; notes that no significant relationship between the study variables . Finally in terms of psychological abuse and self-esteem with a $\mathrm{p}=$ 0.914 , it is evident that there is significant relationship between the study variables.

KEYWORDS: physical and psychological abuse , self-esteem, assertiveness, student.

\section{INTRODUCCIÓN}

El maltrato es la expresión de una disfunción en el sistema padres-niño-ambiente y cultura, por lo que es concebido como aquello que sufren los niños ocasional o habitualmente, traducidos en actos de violencia física, psicológica, sexual o emocional, el maltrato puede ser ejecutado por omisión, supresión o trasgresión de los derechos individuales y colectivos e incluye el abandono completo o parcial.

Este fenómeno, que atenta contra los derechos de los segmentos más vulnerables de la sociedad, se registra, por lo general, en los espacios más íntimos de la convivencia familiar, en nuestro entorno existe maltrato hacia el niño justificados por diferentes causas: desobediencia, incompatibilidad de caracteres, presencia de los padrastros, el alcoholismo, mal comportamiento y otros, dañando física y psicológicamente al niño. Algunos sectores de la sociedad han entendido al maltrato infantil como parte del modelo familiar de educación-disciplina, en tal orden de ideas, existen quienes argumentan que, en términos de un castigo a los hijos “desobedientes", es una práctica cultural en nada cuestionable.

A menudo el daño emocional severo de los niños maltratados no se refleja hasta la adolescencia, o aún más tarde, cuando muchos de estos niños maltratados se convierten en padres abusivos y comienzan a maltratar a sus propios hijos. Un adulto que fue abusado de niño, tiene mucha dificultad en establecer relaciones íntimas, estas víctimas tanto mujeres como hombres pueden tener problemas para establecer relaciones cercanas, para establecer intimidad y confiar en otros al llegar a la etapa adulta, están expuestos a un mayor riesgo de ansiedad

Este problema social que afecta la salud mental de la víctima, se manifiesta a través de: rebeldía, timidez, perversidad, resentimiento, vergüenza, hipersensibilidad, ansiedad, cambios de humor repentinos, ideas 
autodestructivas, baja autoestima, conductas sumisas o agresivas en las relaciones interpersonales, constituyéndose en una barrera que impide un desarrollo psico-social evolutivo normal de los niños, incluyendo un buen desarrollo de la autoestima; en este contexto se planteó la siguiente interrogante ¿Cuál es la relación que existe entre el maltrato físico-psicológico y la autoestima-asertividad en niños y niñas de las instituciones educativas del área rural de la localidad de Huancavelica, cuyo objetivo fue determinar la relación que existe entre el maltrato físico, psicológico con la autoestima y asertividad en los niños y niñas de las Instituciones Educativas del área rural de la Localidad de Huancavelica.

\section{MATERIALES Y MÉTODOS DISEÑO DE ESTUDIO}

Tipo de investigación observacional, nivel descriptivo; diseño no experimental, prospectivo, correlacional

\section{AREA Y POBLACION}

El Departamento de Huancavelica está ubicada en la sierra central del Perú, localizado en el corazón de los andes, tiene una superficie de 22, $131.47 \mathrm{Km} 2$, su territorio abarca el $1.72 \%$ de espacio peruano y su población representa el $1.66 \%$ del total nacional, teniendo como altitud máxima 5328 m.s.n.m. representado por el nevado de Citac, y como límite inferior 1000 m.s.n.m. en la que se ubican las Provincias de Castrovirreyna y Huaytará. Está ubicada en las coordenadas: $74^{\circ} 58^{\prime} 4^{\prime \prime}$ Longitud Oeste y $12^{\circ} 48^{\prime} 32^{\prime \prime}$ latitud Sur. Conformada por 7 provincias y 96 distritos. En el distrito de Huancavelica, se ubica la localidad de Huancavelica, constituida por los barrios de; Santa Ana, San Cristóbal y Yananaco, en esta última se encuentra la Institución Educativa No 36 009, creada en 1934, de condición pública.

La población estuvo constituida por 22 alumnos(as), las unidades de análisis los constituyeron el total de la población objetivo de las Instituciones Educativas $\mathrm{N}^{\mathrm{o}}$ 36344 y 36475 del área rural empleándose el muestreo criterial, las edades fluctuaron entre 9 y 13 años.

\section{RECOLECCION DE DATOS}

La identificación a las víctimas de maltrato físico y psicológico, se realizó utilizando la técnica de entrevista e instrumento la guía de entrevista, Para identificar a las víctimas de maltrato físico y psicológico, se trabajó en un ambiente separado con cada alumno, para que con toda libertad y resguardando su intimidad pudieran responder y marcar sus respuestas. El Test de Autoestima para Escolares y el Autoinforme de Conducta asertiva (ADCA-1) para medir la autoestima y asertividad en los alumnos, fue aplicado por separado en fechas diferentes y en cuatro grupos de 5 alumnos y dos grupos de 6

\section{ANALISIS ESTADISTICO}

Se procedió a almacenar los datos para el procesamiento y análisis en el PASW Statistic Vers. 18.0, Las pruebas estadísticas no paramétrica usada Ji Cuadrada para la contrastación de la hipótesis, considerando $\mathrm{p}<0,005$.

\section{RESULTADOS}

Del total de encuestados (22) el $45.5 \%$ son de sexo masculino y el $54.5 \%$ de sexo femenino, las edades estuvieron comprendidas entre 9 y 13 años. De la tabla $\mathrm{N}^{\circ}$ 01 se desprende que los niños(as) fueron víctimas de maltrato físico severo en un porcentaje mayor, encontrándose un bajo porcentaje de niños(as) con tendencia a autoestima baja.

Tabla 01. Maltrato físico y autoestima de los niños y niñas de las Instituciones Educativas de nivel primario del área rural de la localidad de Huancavelica- 2010

\begin{tabular}{|c|c|c|c|c|c|c|c|c|c|c|c|c|}
\hline \multirow{3}{*}{$\begin{array}{l}\text { Maltrato } \\
\text { físico }\end{array}$} & \multicolumn{10}{|c|}{$\begin{array}{l}\text { Nivel de autoestima } \\
\end{array}$} & \multirow{2}{*}{\multicolumn{2}{|c|}{ Total }} \\
\hline & \multicolumn{2}{|c|}{$\begin{array}{c}\text { Alta } \\
\text { Autoestima }\end{array}$} & \multicolumn{2}{|c|}{$\begin{array}{c}\text { Tendencia a } \\
\text { alta } \\
\text { autoestima }\end{array}$} & \multicolumn{2}{|c|}{$\begin{array}{c}\text { Autoestima } \\
\text { en riesgo }\end{array}$} & \multicolumn{2}{|c|}{$\begin{array}{c}\text { Tendencia a } \\
\text { baja } \\
\text { autoestima } \\
\end{array}$} & \multicolumn{2}{|c|}{$\begin{array}{c}\text { Baja } \\
\text { autoestima }\end{array}$} & & \\
\hline & fi & f\% & fi & $\mathbf{f} \%$ & fi & f\% & fi & f\% & fi & f\% & fi & $\mathrm{f} \%$ \\
\hline Leve & 0 & 0 & 0 & 0 & 0 & 0 & 0 & 0 & 0 & 0 & $\mathbf{0}$ & $\mathbf{0}$ \\
\hline Moderado & 0 & 0.0 & 1 & 4.5 & 1 & 4.5 & 1 & 4.5 & 0 & 0.0 & 3 & 13.6 \\
\hline Severo & 1 & 4.5 & 4 & 18.2 & 0 & 0.0 & 3 & 13.6 & 1 & 4.5 & 9 & 40.9 \\
\hline $\begin{array}{l}\text { No } \\
\text { maltratado }\end{array}$ & 0 & 0.0 & 7 & 31.8 & 1 & 4.5 & 2 & 9.1 & 0 & 0.0 & 10 & 45.5 \\
\hline Total & 1 & 4.5 & 12 & 54.5 & 2 & 9.1 & 6 & 27.3 & 1 & 4.5 & 22 & 100.0 \\
\hline
\end{tabular}

Fuente: Guía de entrevista de Identificación de Maltrato Infantil y Test de Autoestima para Escolares, 2010 
El maltrato psicológico severo predomino, caracterizado por insultos, críticas, descréditos, ridiculizaciones, así como la indiferencia y el rechazo explícito o implícito hacia el niño o niña ejercido por los padres, hermanos, amigos, tíos, primas (os), etc. Las víctimas de maltrato psicológico en sus diferentes categorías, mostraron una fluctuación de la autoestima entre la tendencia a la autoestima alta, así como a una autoestima baja, con respecto a la asertividad mostraron un nivel medio, como se observa en la Tabla $\mathrm{N}^{\circ} 02$.

Tabla $N^{\circ}$ 02. Maltrato psicológico y Autoestima de los niños y niñas de las Instituciones Educativas de nivel primario del área rural de la localidad de Huancavelica-2010.

\begin{tabular}{|c|c|c|c|c|c|c|c|c|c|c|c|c|}
\hline \multirow{3}{*}{$\begin{array}{c}\text { Maltrato } \\
\text { psicológico }\end{array}$} & \multicolumn{10}{|c|}{ Nivel de autoestima } & \multirow{2}{*}{\multicolumn{2}{|c|}{ Total }} \\
\hline & \multicolumn{2}{|c|}{$\begin{array}{c}\text { Alta } \\
\text { Autoestima }\end{array}$} & \multicolumn{2}{|c|}{$\begin{array}{l}\text { Tendencia a } \\
\text { alta autoestima }\end{array}$} & \multicolumn{2}{|c|}{$\begin{array}{l}\text { Autoestima } \\
\text { en riesgo }\end{array}$} & \multicolumn{2}{|c|}{$\begin{array}{c}\text { Tendencia a } \\
\text { baja } \\
\text { autoestima }\end{array}$} & \multicolumn{2}{|c|}{$\begin{array}{c}\text { Baja } \\
\text { autoestima }\end{array}$} & & \\
\hline & fi & $\mathbf{f} \%$ & fi & $\mathbf{f} \%$ & fi & f\% & fi & f\% & fi & $f \%$ & fi & $\mathbf{f} \%$ \\
\hline Leve & 0 & 0.0 & 2 & 9.1 & 0 & 0.0 & 1 & 4.5 & 0 & 0.0 & 3 & 13.6 \\
\hline Moderado & 0 & 0.0 & 1 & 4.5 & 0 & 0.0 & 2 & 9.1 & 0 & 0.0 & 3 & 13.6 \\
\hline Severo & 0 & 0.0 & 4 & 18.2 & 1 & 4.5 & 1 & 4.5 & 0 & 0.0 & 6 & 27.3 \\
\hline No maltrato & 1 & 4.5 & 5 & 22.7 & 1 & 4.5 & 2 & 9.1 & 1 & 4.5 & 10 & 45.5 \\
\hline Total & 1 & 4.5 & 12 & 54.5 & 2 & 9.1 & 6 & 27.3 & 1 & 4.5 & 22 & 100.0 \\
\hline
\end{tabular}

Fuente: Guía de entrevista de Identificación de Maltrato Infantil y Test de Autoestima para Escolares, 2010

Con respecto al Maltrato físico y la asertividad, las víctimas de maltrato severo evidenciaron una asertividad de nivel medio. Tabal No 03

Tabla $\mathrm{N}^{0}$ 03. Maltrato físico y asertividad de los niños y niñas de las instituciones Educativas de nivel primario del área rural de la localidad de Huancavelica-2010

\begin{tabular}{|c|c|c|c|c|c|c|}
\hline \multirow{3}{*}{ Maltrato físico } & \multicolumn{4}{|c|}{ Asertividad } & \multirow{2}{*}{\multicolumn{2}{|c|}{ Total }} \\
\hline & \multicolumn{2}{|c|}{ Alto } & \multicolumn{2}{|c|}{ Medio } & & \\
\hline & fi & $\mathbf{f} \%$ & fi & $\mathbf{f} \%$ & fi & $\mathbf{f} \%$ \\
\hline Moderado & 1 & 4.5 & 2 & 9.1 & 3 & 13.6 \\
\hline Severo & 0 & 0.0 & 9 & 40.9 & 9 & 40.9 \\
\hline No maltratado & 7 & 31.8 & 3 & 13.6 & 10 & 45.5 \\
\hline Total & 8 & 36.4 & 14 & 63.6 & 22 & 100.0 \\
\hline
\end{tabular}

Fuente: Guía de entrevista de Identificación de Maltrato Infantil y Autoinforme de Conducta Asertiva, 2010

Finalmente con respecto al maltrato psicológico y la asertividad, se aprecia un que en todas sus categorías predomino el nivel medio de asertividad. Tabla $\mathrm{N}^{\circ} 04$.

Tabla $\mathbf{N}^{0}$ 04. Maltrato psicológico y asertividad de los niños y niñas de las Instituciones Educativas de nivel primario del área Rural de la localidad de Huancavelica-2010

\begin{tabular}{|c|c|c|c|c|c|c|}
\hline \multirow{3}{*}{ Maltrato psicológico } & \multicolumn{4}{|c|}{ Asertividad } & \multirow{2}{*}{\multicolumn{2}{|c|}{ Total }} \\
\hline & \multicolumn{2}{|c|}{ Alto } & \multicolumn{2}{|c|}{ Medio } & & \\
\hline & fi & $f \%$ & fi & $f \%$ & fi & $f \%$ \\
\hline Leve & 2 & 9.1 & 1 & 4.5 & 3 & 13.6 \\
\hline Moderado & 0 & 0.0 & 3 & 13.6 & 3 & 13.6 \\
\hline Severo & 1 & 4.5 & 5 & 22.7 & 6 & 27.3 \\
\hline No maltrato & 5 & 22.7 & 5 & 22.7 & 10 & 45.5 \\
\hline Total & 8 & 36.4 & 14 & 63.6 & 22 & 100.0 \\
\hline Total & 8 & 36.4 & 14 & 63.6 & 22 & 100.0 \\
\hline
\end{tabular}




\section{DISCUSIÓN:}

En el presente trabajo de investigación se tuvo un total de 22 unidades de análisis, de los cuales $45.5 \%$ fueron de sexo masculino y $54.5 \%$ fueron de sexo femenino. Las edades estuvieron comprendidas entre 9 y 13 años cabe señalar que no se realizó ningún tamizaje para abordar esta problemática.

Para los niños, los padres son quienes poseen todo el conocimiento, el control de los recursos y la fuerza física. Los padres son también, su fuente más importante de afecto; por lo que negarles cariño o amenazarlos tiene gran efecto y poder sobre ellos, como menciona Jara, L. (1) los niños identifican los insultos, desprecios y golpes de los padres como una falta de amor, sintiéndose impotentes y desanimados para enfrentar estas experiencias, llegando incluso a interiorizar la imagen desvalorizada que les es transmitida de ellos mismos. Esta apreciación puede verse reflejado en la tabla $\mathrm{N}^{\mathrm{o}} 01$ en el que se observa que el $49.9 \%$ de los niños (as) sufrieron maltrato físico severo y $13.6 \%$ fueron víctimas de maltrato físico moderado. El cual es reforzado por el trabajo de Vizcarra, M. Cortés, J. Bustos, L Alarcón, M. Muñoz, S. (2) quienes demostraron en 422 hogares la presencia de la violencia física leve en un $42,3 \%$ de las madres y $17,1 \%$ de los padres. E1 2,6\% de las madres y $1,2 \%$ de los padres reconocieron ejercer violencia grave contra sus hijos como golpes con palos, cinturón, patadas, apretón del cuello con las manos, paliza con el puño u objetos. Estos actos de violencia física dejan huellas imborrables en la psiqui de los niños(as), teniendo mucha dificultad para relacionarse con los otros debido a que en principio, no han logrado establecer una relación de apego seguro con sus padres; a la vez, son niños que no cuentan con la tranquilidad de sentirse queridos; y a modo de defensa, se quedan en un estado narcisista que no les permite reconocer al otro, así como ellos no fueron reconocidos. Por lo mismo, les es difícil entender la cercanía emocional y esperar que las demás personas se relacionen con ellos positivamente.

De otro lado en la misma tabla podemos observar que los niños (as) que fueron víctimas de maltrato físico severo mostraron el $4.5 \%$ autoestima alta, $18.2 \%$ tendencia autoestima alta, $13.6 \%$ tendencia a autoestima baja y $4.5 \%$ autoestima baja. Con respecto a los que sufrieron maltrato físico moderado mostraron $4.5 \%$ tendencia autoestima alta, autoestima en riesgo y tendencia a autoestima baja respectivamente. Según Calero(3) la Autoestima es siempre una experiencia intima, es lo que pensamos y sentimos con respecto a nosotros mismos, no lo que otra persona piensa con respecto a nosotros. Al hablar de autoestima estamos hablando de amor propio que comprende ideas y sentimientos, acerca de sí mismo, ellos pueden ser positivos, por ejemplo "soy linda", "inteligente", "aprendo de mis errores" " "soy sociable" y mientras más positivos sean los sentimientos que tengamos "mayor es nuestro amor propio". Pero también las ideas o sentimientos que tenemos de nosotros mismos pueden ser negativos, por ejemplo "soy aburrido", "nadie me quiere", mientras más negativos sean nuestros sentimientos menor será nuestro amor propio. La autoestima se va construyendo a partir de las personas que nos rodean, de las experiencias, vivencias y sentimientos que se producen durante todas las etapas de la vida, siendo la más importante para su adquisición la infancia y la adolescencia”. Las edades de las víctimas de maltrato fluctuaban entre $9 \mathrm{y}$ 13 años; comprendidas entre la pubertad y la adolescencia, trayendo consigo una historia de maltrato físico, esto viene produciéndose como una forma de vida en las familias de estos niños(as), afectando su autoestima como lo refleja el $13.6 \%$ de niños(as) que tienen tendencia a autoestima baja y $4.5 \%$ a una autoestima baja, vulnerando sus derechos a una vida saludable e imposibilitando el desarrollo de su autoconcepto es decir la imagen que tienen de si mismo en lo físico, intelectual, social, etc., afectando la formación de una estructura funcional mental eficaz y sólida, estos resultados encontrados se correlacionan con el trabajo realizado por Huamán M.(4) quien señala que el 24.7\% de niños víctimas de maltrato físico, presentaron una autoestima bajo y moderado respectivamente y solo el $1.8 \%$ presento una autoestima alto.

La autoasertividad como una de las dimensiones de la asertividad, es el grado en el que una persona se concede los derechos asertivos básico, por ejemplo cuando hace algo y no siente vergüenza de lo que puedan pensar de él (ella), no se enfada si no consigue hacer las cosas bien o cuando se equivoca y no le cuesta reconocerlo ante los demás, de las víctimas de maltrato físico severo, el $40.9 \%$ presentaron una autoasertividad medio, las víctimas de maltrato físico moderado presentaron autoasertividad $4.5 \%$ alto y $9.1 \%$ medio, apreciándose que muchos de los derechos que les es inherente no lo conocen por lo tanto no lo practican. El microsistema inmediato al niño es la familia y constituye el primer eslabón en el aprendizaje de los derechos empezando por el respeto a sí mismo, cuando 
este ambiente es hostil y/o violento los niños(as) no encuentra modelos de aprendizaje constructivos, por lo van construyen en su esquema mental que la violencia es normal y parte de la vida que les tocó vivir, es mas en muchos casos viven en un círculo vicioso de amor y odio con los agresores. Mostrando poca capacidad para enfrentarse a situaciones y en su mayoría aumentan sus niveles de ansiedad social, cuando establecen una comunicación con alguien por lo general creen que no deben mirar a los ojos, no levantan la cara, la voz es de volumen bajo y tono débil con miedo, adoptando una postura contraída que suele ser señal de timidez o abatimiento físico o psíquico.

La heteroasertividad como el grado en que una persona considera que los demás también tienen derechos asertivos básicos, como "no le debe irritar que le lleven la contraria", "no debe disgustarle que lo critiquen" o " no debe enfadarse cuando comprueba la ignorancia de los demás". Los niños(as) víctimas de maltrato físico severo, presentaron una heteroasertividad $31.8 \%$ medio y $9.1 \%$ baja y los niños con maltrato físico moderado presentaron $4.5 \%$ alto y $9.1 \%$ medio. Por lo general estos niños(as) se irritan cuando alguien le lleva la contraria, se ofenden cuando lo critican, busca muchas excusas cuando comete errores, le da mucha atención a los demás cuando no comprenden sus sentimientos o razones, dejando graficado que un buen porcentaje de niños(as) olvidan que las personas que le rodean también tienen derechos y no solo ellos (ellas).

La conducta asertiva es la expresión directa de los propios sentimientos, deseos, derechos legítimos y opiniones sin amenazar o castigar a los demás. Implica respeto hacia uno mismo al expresar necesidades propias y defender los propios derechos y respeto hacia las necesidades y derechos de las otras personas.

Los resultados de los niños víctimas de maltrato físico severo, mostraron una asertividad de $40.9 \%$ medio, en contraste con las víctimas de maltrato físico moderado que mostraron una asertividad $4.5 \%$ alta y $9.1 \%$ medio; datos que se correlacionan con el estudio sobre Maltrato infantil y nivel de asertividad en alumnos de la Institución Educativa José María Arguedas(5) quienes señalan que el 50.8\% fueron víctimas de maltrato psicológico, $42.4 \%$ de maltrato psicológico y $6.8 \%$ de abuso sexual. 5.7\% de víctimas de maltrato físico, $11.0 \%$ de víctimas de maltrato psicológico y $5.7 \%$ de víctimas de abuso sexual presentaron baja asertividad. El $37.5 \%$ de víctimas de maltrato físico. $29.5 \%$ víctimas de maltrato psicológico y el $1.1 \%$ de víctimas de abuso sexual presentaron asertividad media. Finalmente solo el $7.6 \%$ de víctimas de maltrato físico, $1.9 \%$ de víctimas de maltrato psicológico presentaron alta asertividad. Los niños(as) víctimas de maltrato físico generan sentimientos de culpa, constante ira o miedo hacia los agresores(as), muestran comportamientos destructivos, mostrando mucha dificultad para expresar abiertamente sus sentimientos, pensamientos y opiniones o al expresarla la hacen de una manera autoderrotista con disculpas, con falta de confianza. El ser asertivo la capacidad de comunicarse con libertad, acepta sus limitaciones, se aprecia y se acepta a si mismo tal y como es, establecen quienes van a ser sus amigos y quienes no, evita los extremos por un lado la represión y por el otro la expresión agresiva y destructiva, encontrándose un mínimo porcentaje de niños con esta habilidad social caracterizada por una asertividad alta.

El maltrato psicológico se caracteriza por el hostigamiento verbal habitual por medio de insultos, críticas, descréditos, ridiculizaciones, así como la indiferencia y el rechazo explícito o implícito hacia el niño, niña o adolescente ejercido por los padres, hermanos, amigos, tíos, primas(os), etc. También se incluye el rechazo, el aislamiento, aterrorizar a los niños o niñas, ignorarlos y corromperlos, estos actos causan o puedan causar deterioro en el desarrollo emocional, social o intelectual del niño. De la tabla y N ${ }^{o} 02$ se desprende que los niños(as) víctimas de maltrato psicológico según categorías tenemos $3 \%$ leve, $3 \%$ moderado y $6 \%$ severo, algunos estudios que corroboran la existencia de este flagelo social son; el estudio realizado sobre maltrato infantil y autoestima en los niños en I.E públicas de la Localidad de Huancavelica, señalando la presencia de maltrato psicológico severo $15.4 \%$, el $7.5 \%$ fueron víctimas de maltrato psicológico moderado y el 5.7\% leve(4) Así mismo el estudio sobre Maltrato infantil y nivel de asertividad en alumnos de la Institución Educativa José María Arguedas - Lircay quienes refieren que el 50.8\% fueron víctimas de maltrato físico, $42.4 \%$ de maltrato psicológico y $6.8 \%$ de abuso sexual.(5)

También en esta tabla se aprecia que las víctimas de maltrato psicológico severo mostraron $18.2 \%$ tendencia a alta autoestima, $4.5 \%$ autoestima en riesgo y tendencia a baja autoestima. En relación a las víctimas de maltrato psicológico moderado encontramos $4.5 \%$ con tendencia autoestima alta y $9.1 \%$ con tendencia autoestima baja. Finalmente tenemos a las víctimas con maltrato psicológico leve quienes mostraron $9.1 \%$ con tendencia autoestima alta y $4.5 \%$ con tendencia autoes- 
tima baja. El estudio realizado sobre maltrato infantil y autoestima en los niños en la Localidad de Huancavelica,(4) refieren que las víctimas de maltrato físico, psicológico y sexual el $50.2 \%$ de los niños(as), presentan un nivel de autoestima bajo, seguido del 37.4\% que presentaron un autoestima normal o medio y solo un $12.3 \%$ presentaron un autoestima alto; si bien estos datos no son tan similares al reportado en el presente trabajo, es importante señalar que los niños que sufren de maltrato psicológico de parte de sus cuidadores, son exageradamente temerosos y ansiosos; y las experiencias nuevas, aunque sean positivas, les provocan excitación y ansiedad desmesurada, con poca frecuencia demuestran alegría o placer, y se caracterizan por aparecer siempre frustrados y tristes, además manifiestan sentimientos de fracaso y vergüenza frente a sus dificultades de aprendizaje. El niño que no es amado, además de tener una mala imagen de sí mismo, percibe al mundo como amenazante y poco seguro.

En cuanto a la dimensión de autoaserttividad de la asertividad, las víctimas de maltrato psicológico severo, moderado y leve mostraron una autoasertividad de $27.2 \%, 13.6 \% 4.5 \%$ medio respectivamente, indicándonos que los niños(as) no conocen y por lo tanto no practican sus derechos asertivos básicos en su totalidad, quizás esto se explique por su forma de vivir en conflicto, con violencia que para nada contribuye en el desarrollo de sus capacidades y por ende en el desarrollo de la habilidad social, empezando por respetarse a si mismo. Los niños expuestos a abuso verbal, cohíben poco a poco sus manifestaciones espontáneas y suprimen algunos aspectos de la conducta interpersonal, lo que explicaría el enlentecimiento en la adquisición de competencias cognitivas. Algunos estudios han revelado déficit significativos en el rendimiento académico y en el nivel intelectual de los niños maltratados física y psicológicamente. Las situaciones carenciales o de maltrato psicológico, obligan a los menores a invertir gran cantidad de energía psíquica en desarrollar mecanismos de adaptación a su situación, como por ejemplo en las relaciones interpersonales caracterizadas por la dependencia y el rechazo. Ésta aparece a raíz de la indiferencia de los padres, por lo cual el niño puede ser muy dependiente de los signos de afecto de cualquier adulto, llamando su atención indiscriminadamente para procurarse un poco de afecto, exponiéndose permanentemente al peligro de rechazo. Una vez lograda la atención del adulto, la dependencia se transforma en retirada, para protegerse del sufrimiento que puede conllevar un nue- vo abandono. Así, estos niños dejan paulatinamente de buscar afecto y congelan sus emociones, negándose la posibilidad de mantener relaciones afectivas, cálidas y duraderas en el transcurso de su vida.

Respecto de la dimensión de heteroasertividad, las víctimas de maltrato psicológico severo presentaron una heteroasertividad de $9.1 \%$ medio y $18.2 \%$ bajo. En cuanto a las víctimas de maltrato psicológico moderado la heteroasertividad encontrada fue de $13.6 \%$ en el nivel medio y las víctimas de maltrato psicológico leve mostraron una heteroasertividad de $9.1 \%$ alto y $4.5 \%$ medio. Es preciso señalar el nivel medio obtenido en esta dimensión por las víctimas de maltrato psicológico, es un indicativo de que los niños van creciendo y construyendo que los demás no tienen derechos asertivos básicos, por lo que siempre se mueven entre una conducta pasiva y una conducta agresiva, y en muy pocas circunstancias en el marco de una conducta asertiva.

Las víctimas de maltrato psicológico severo $4.5 \%$ mostraron una asertividad alto y $22.7 \%$ medio, las víctimas de maltrato psicológico moderado $13.6 \%$ mostraron una asertividad medio y las víctimas de maltrato psicológico leve mostraron $9.1 \%$ alto y $4.5 \%$ medio. Según El estudio realizado por PUGA. L(6) reporto que los niños que recibieron castigo físico y emocional tienen el deseo de vincularse con otros pero presentan dificultades para establecer patrones de relación eficaces ya que no respetan la autonomía de los demás, así mismo encontraron vivencias de agresión muy presentes a nivel subjetivo, por lo que observaron que los niños que recibieron castigo físico y emocional tendían a mantener actitudes hostiles en sus relaciones, así como a sentirse vulnerables y temerosos ante la posibilidad de actos violentos. Encontraron también que los niños presentan dificultades para reconocer y expresar afectos positivos, a la vez que presentan una visión distorsionada del mundo, percibiendo su ambiente de manera pesimista y desesperanzadora. De otro lado observaron dificultades cognitivas en relación al pensamiento lógico y al juicio, lo cual puede entorpecer la interacción al no compartir los mismos esquemas mentales que otros niños. De acuerdo a los resultados obtenidos al hablar de la asertividad en las víctimas de maltrato psicológico en sus diferentes categorías predomina el nivel medio, se podría decir que estos niños al no ser asertivos en un nivel alto, albergan elevados niveles de agresión y vulnerabilidad ante la posibilidad de ser dañados, la interrelación con los demás puede convertirse en una 
fuente considerable de estrés en la vida.

\section{CONCLUSIONES}

1. Las unidades de unidades de análisis, no sufrieron ningún tamizaje, teniendo un mayor porcentaje de participantes de sexo femenino y el menor de seo masculino. La edad mínima encontrada fue de 9 años y la máxima de 13 años de edad.

2. Los niños(as) fueron víctimas de maltrato físico severo en un porcentaje mayor. Así mismo se encontró un bajo porcentaje de niños(as) con tendencia a autoestima baja y a una autoestima baja.

3. Los resultados de los niños víctimas de maltrato físico en sus diferentes categorías mostraron un mayor porcentaje de asertividad en el nivel medio

4. Las víctimas de maltrato psicológico en sus diferentes categorías, mostraron una fluctuación de la autoestima entre la tendencia a la autoestima alta, así como a una autoestima baja.

5. Las de víctimas de maltrato psicológico en sus diferentes categorías mostraron una asertividad en un nivel medio.

6. Se la prueba estadística no paramétrica Ji Cuadrada, a un nivel de significancia de 0,005 en primera instancia se afirma la asociación significativa entre el maltrato físico y nivel de asertividad, Mas no se evidencio asociación entre el maltrato físico y nivel de autoestima; como tampoco lo hay entre el maltrato psicológico y el nivel de asertividad, del mismo modo sucedió con el maltrato psicológico y el nivel de autoestima.

\section{REFERENCIAS BIBLIOGRÁFICAS}

1. Jara, L. Representaciones sobre el maltrato infantil en niños limeños y andinos a través de sus dibujos. Tesis para optar por el título de Magíster, Pontificia Universidad Católica del Perú. Lima: PUCP; 2008.

2. Vizcarra, M. Cortés, J. Bustos, L Alarcón, M. Muñoz, S. Maltrato infantil en la ciudad de Temuco. Revista Médica de Chile, ISSN 0034-9887 versión impresa Rev. méd. Chilena v. 129 n.12 Santiago; 2001.

3. Calero, M. Autoestima y docencia. Edit. San Marcos Lima; 2000, pág. 28 -pág. 20.

4. Huamán M. Maltrato infantil y autoestima en los niños de las Instituciones Educativas estatales de la Localidad de Huancavelica. [Tesis post grado] Huancavelica. Universidad Nacional San Agustín de Arequipa. 2006.
5. Belito E. Maltrato infantil y nivel de asertividad en alumnos de la Institución Educativa José María Arguedas. Lircay. [Tesis de pre grado]. Huancavelica: Universidad Nacional de Huancavelica; 2009.

6. Puga L. Relaciones interpersonales en un grupo de niños que reciben castigo físico y emocional. UNMSM Facultad de Letras y Ciencias Humanas. Especialidad de Psicología. [Tesis de pregrado] Lima; 2008.

Fecha de recepción: 02/04/15

Fecha de aprobación: 06/05/15

Correspondencia: Huamán Albites Margarita Isabel

Email: margaritaisabel_2008@hotmail.com 